\title{
Aplikasi Penjualan Pulsa Elektronik Berbasis Android
}

\author{
Dwi Teguh Prasetyo ${ }^{1}$, Nur Zahrati Janah², Supardianto ${ }^{3}$ \\ * Teknik Informatika, Politeknik Negeri Batam \\ dtprasetyoo@gmail.com ${ }^{1}$,nur.zahrati@gmail.com ${ }^{2}$, supardianto@polibatam.ac.id ${ }^{3}$
}

\begin{tabular}{|c|c|}
\hline Article Info & ABSTRACT \\
\hline Article history: & \multirow{9}{*}{$\begin{array}{l}\text { Nowadays, a mobile phone has transformed into a smartphone and not only used for } \\
\text { communication. Further, then that, the mobile phone becomes a versatile item. You } \\
\text { can use a mobile phone for browsing on the internet, you can pay something you buy } \\
\text { using a mobile phone, you can order something you want via mobile phone, etc. } \\
\text { everything gets easier because we can use mobile phone wherever and whenever we } \\
\text { need. And to support the use of mobile phones, we need credit as a payment. Mobile } \\
\text { credit transaction application for Android Devices is an application with user- } \\
\text { friendly design and can make the credit's seller easier to top up customer's credit. } \\
\text { This application can be used on an Android smartphone with minimal version } \\
\text { android KitKat. The benefit of this application is to facilitate and accelerate the } \\
\text { transaction credit delivery by the seller. This application is expected to facilitate the } \\
\text { credit's seller doing transaction by providing a transaction history, mark the } \\
\text { customer's debt and reports a valid seller's income as well as provide a report format } \\
\text { the transaction automatically after the user do some settings at the beginning of the } \\
\text { use of the application. }\end{array}$} \\
\hline Received 2017-10-18 & \\
\hline Revised 2018-06-17 & \\
\hline Accepted 2018-07-01 & \\
\hline Keyword: & \\
\hline android; & \\
\hline application; & \\
\hline credit; & \\
\hline top up. & \\
\hline
\end{tabular}

Copyright (C) 2017 Journal of Applied Informatics and Computing. All rights reserved.

\section{Pendahuluan}

Teknologi ponsel saat ini telah mengalami perkembangan yang cukup pesat, dimana awalnya sebagai perangkat komunikasi. Saat ini ponsel tidak lagi hanya diperuntukkan sebagai perangkat komunikasi, namun dapat digunakan sebagai perangkat pintar untuk membuat pekerjaan menjadi lebih mudah. Perangkat pintar atau atau dikenal dengan smartphone dapat digunakan untuk menjelajah (browsing) sesuatu, mengambil foto, mengunggah ke media sosial, memesan makanan, mencari pekerjaan, bermain game, payment, dll. Sebagian besar smartphone di dunia, menggunakan Android sebagai sistem operasinya. Selain itu juga smartphone juga membutuhkan pulsa sebagai alat pembayaran untuk menggunakan ponsel. Lebih banyak internet yang dikonsumsi, maka lebih banyak pulsa yang dibutuhkan. Karena itu, penjual pulsa menjadi semakin banyak. Penjualan pulsa adalah salah satu bisnis dengan modal kecil yang dapat dilakukan setiap orang. Namun sayang, sebagian besar penjual pulsa saat ini, melakukan transaksi pembelian pulsa dengan sistem manual yaitu mencatat riwayat transaksi dalam sebuah buku. Dipisahkan dengan ponsel yang berfungsi untuk mengirim pesan permintaan pengisian pulsa dalam bentuk SMS ke server penyedia pulsa. Hal ini tentunya sulit bagi penjual pulsa dalam menghitung pendapatan dari penjualan pulsa. Ditambah lagi jika penjual lupa bahwa ada pelanggan yang belum melunasi hutangnya, maka merugikan penjual. Masalah lain yang penulis temukan dalam transaksi penjualan pulsa adalah penjual kesulitan mengingat format transaksi yang sesuai dengan yang telah ditentukan oleh server penyedia pulsa. Penjual selalu mengetik ulang seluruh format transaksi dari kode pengisian setiap kali melakukan transaksi baru. Jika penjual salah memasukkan format, maka pulsa tidak akan masuk ke nomor tujuan atau terkadang bisa memasukkan nomor tujuan yang salah.

\section{DASAR TEORI}

\section{A. Short Message Service (SMS)}

Short Message Service (SMS) merupakan salah satu fasilitas dari teknologi Global System for Communication (GSM) yang memungkinkan mengirim dan menerima pesanpesan singkat berupa teks dengan kapasitas maksimal 160 karakter dari Mobile Station (MS). Kapasitas maksimal ini tergantung dari alphabet yang digunakan, untuk alphabet 
latin maksimal 160 karakter, dan untuk non latin seperti alphabet arab atau china maksimal 70 karakter.

\section{B. Unified Modeling Language (UML)}

UML merupakan Bahasa visual untuk pemodelan dan komunikasi mengenai sebuah sistem dengan menggunakan diagram dan teks-teks pendukung. Secara fisik, UML adalah sekumpulan spesifikasi yang dikeluarkan oleh Object Management Group (OMG), sebuah konsorsium terbuka yang terdiri dari banyak perusahaan [1]. UML biasa digunakan untuk [3]:

- Menggambarkan batasan sistem dan fungsi-fungsi sistem secara umum, dibuat dengan use case dan aktor.

- Menggambarkan kegiatan atau proses bisnis yang dilaksanakan secara umum, dibuat dengan interaction diagrams.

- Menggambarkan representasi struktur statik sebuah sistem dalam bentuk class diagram.

- Membuat model behaviour yang menggambarkan kebiasaan atau sifat sebuah sistem dengan state transition diagram.

- Menyatakan arsitektur implementasi fisik menggunakan component dan deployment diagram.

\section{Basis Data (Database)}

Basis data adalah sistem terkomputerisasi yang tujuan utamanya adalah memelihara data yang sudah diolah atau informasi dan membuat informasi tersedia saat dibutuhkan. Pada intinya, basis data adalah media untuk menyimpan data agar dapat diakses dengan mudah dan cepat [1].

Basis data mempunyai komponen utama, untuk lebih jelasnya berikut adalah komponen utama sistem basis data terdiri dari:

- Perangkat Keras (hardware)

- Sistem Operasi (Operating system)

- Basis Data (database)

- $\quad$ Sistem (Aplikasi/Perangkat Lunak) Pengelola Bisnis Data (DBMS)

- Pemakai (user) serta aplikasi (perangkat lunak) lain (bersifat opsional)

\section{ANALISIS DAN PERANCANGAN}

\section{A. Deskripsi Umum Sistem}

Aplikasi penjualan pulsa elektronik ini bekerja dengan cara mengirimkan SMS permintaan pengiriman pulsa ke server penyedia pulsa. Format transaksi kode pengisian pulsa untuk setiap operator telah tersimpan di dalam aplikasi. Penjual hanya perlu memverifikasi kode prefix masingmasing operator, kemudian aplikasi akan menyimpan kode prefix tersebut dan akan digunakan setiap kali ingin melakukan pengiriman pulsa pelanggan.

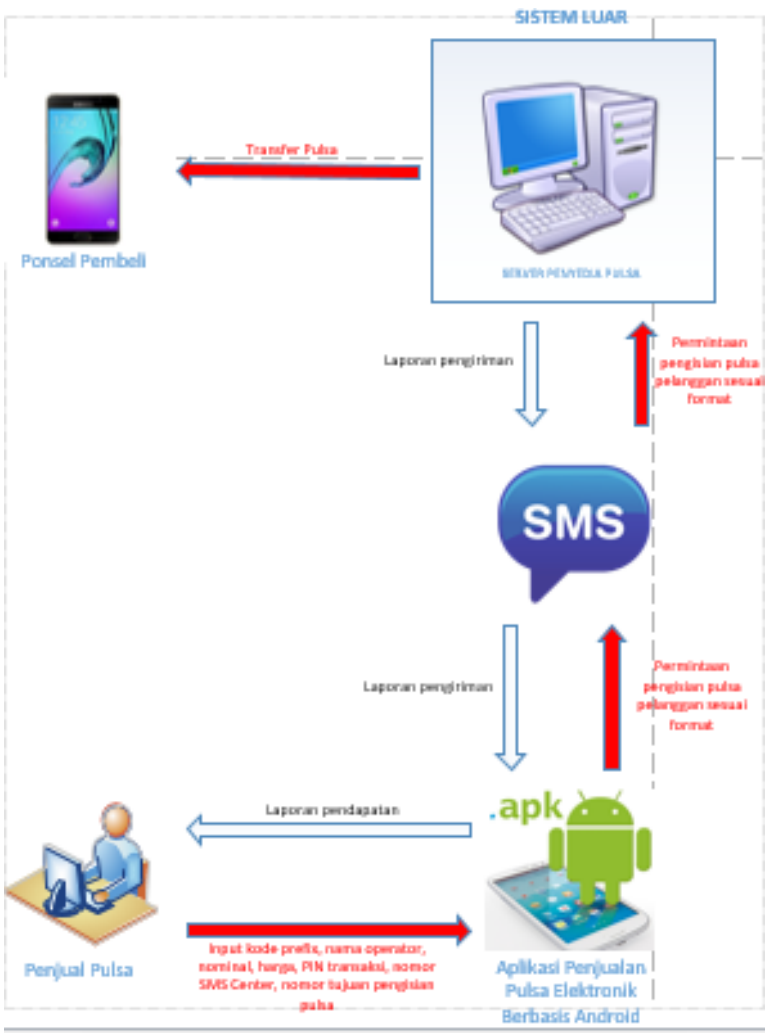

Gambar 1. Deskripsi Umum Sistem

Pada saat penjual ingin menggunakan aplikasi, penjual harus melakukan beberapa pengaturan terlebih dahulu untuk memperlancar proses transaksi. Yaitu melakukan pengaturan kode prefix setiap operator, pengaturan harga setiap nominal pulsa, pengaturan SMS Center sebagai nomor tujuan SMS permintaan pengiriman pulsa, dan mengatur PIN transaksi pulsa penjual yang telah terdaftar sebagai agen penjualan pulsa. Setelah melakukan transaksi, server penyedia pulsa akan mengirim SMS ke ponsel penjual yang berisi laporan pengiriman pulsa telah sukses ataupun gagal. Untuk kebutuhan perhitungan pendapatan penjualan, aplikasi akan menghitung total harga berdasarkan pengaturan harga yang sebelumnya telah diatur oleh penjual dan menghitung transaksi dimana status pembayarannya telah lunas kemudian menampilkannya selama periode waktu tertentu.

\section{B. Kebutuhan Fungsional}

F001 Aplikasi memiliki fitur login.

F002 Aplikasi memiliki fitur pengubahan kata sandi aplikasi.

F003 Aplikasi dapat melakukan permintaan pengisian pulsa Telkomsel, Indosat, XL, Three, SmartFren, Flexi, Axis, Esia, Starone.

F004 Aplikasi melakukan transaksi pulsa melalui SMS

F005 Aplikasi dapat menyimpan format transaksi pulsa melalui SMS untuk setiap operator. 
F006 Aplikasi dapat menyimpan riwayat transaksi penjualan pulsa.

F007 Aplikasi dapat menghitung pendapatan penjual dari penjualan pulsa.

F008 Aplikasi harus dapat merekam dan menyimpan rekaman waktu transaksi.

F009 Aplikasi memiliki fitur untuk menandai pelanggan yang sudah melunaskan pembayaran atau belum.

F010 Aplikasi menyediakan fitur untuk mengubah status pembayaran.

F011 Aplikasi dapat menghapus data transaksi yang telah dipilih oleh penjual.

F012 Aplikasi dapat menampilkan pesan SMS yang masuk ke kartu GSM yang digunakan penjual.

F013 Aplikasi harus memiliki fitur untuk cek saldo.

F014 Aplikasi dapat mengimport data nomor handphone dan nama dari kontak yang telah tersimpan pada ponsel penjual.

F015 Aplikasi dapat menyimpan PIN transaksi pengiriman pulsa.

F016 Aplikasi memiliki fitur pengubahan PIN transaksi pengiriman pulsa.

\section{Kebutuhan Non Fungsional}

NF001 Aplikasi diakses dalam bahasa Indonesia.

NF002 Aplikasi harus mudah dioperasikan.

NF003 Tampilan aplikasi mudah dimengerti oleh penjual.

NF004 Aplikasi memiliki keamanan yang baik.

\section{Use Case Diagram}

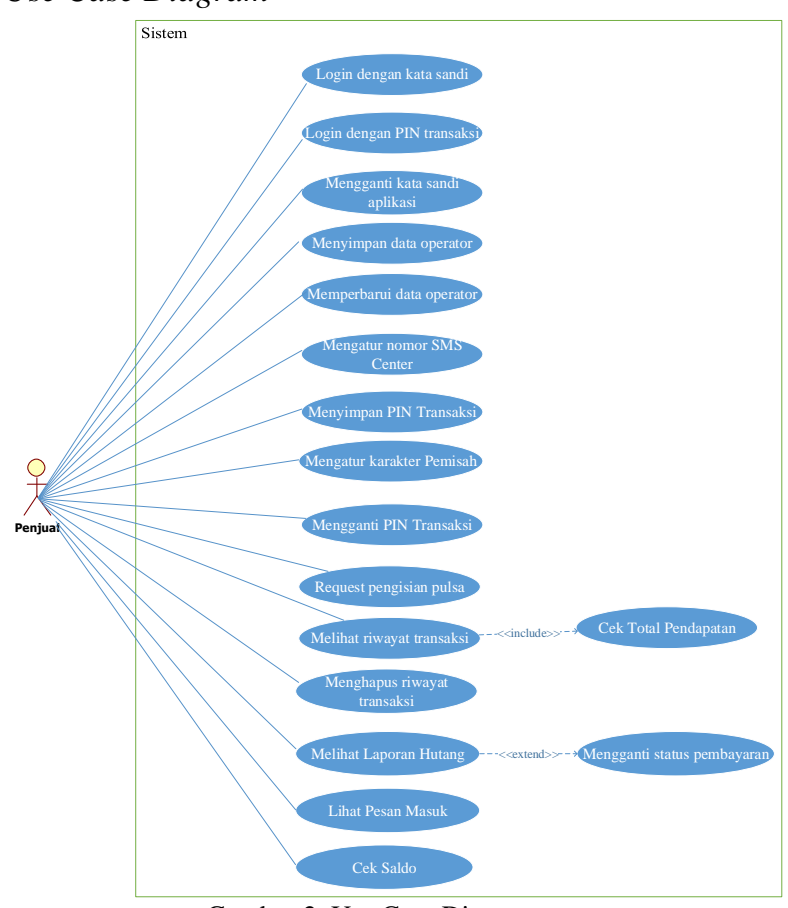

Gambar 2. Use Case Diagram
Gambar 2 menunjukkan diagram use case yang menggambarkan fungsi/layanan yang diharapkan ada pada aplikasi dan hubungannya dengan aktor. Aktor sebagai pengguna aplikasi ini adalah penjual pulsa, yang dapat melakukan 17 fungsi atau layanan yang ada pada pada aplikasi penjualan pulsa elektronik berbasis Android.

\section{E. Entity Relationship Diagram (ERD)}

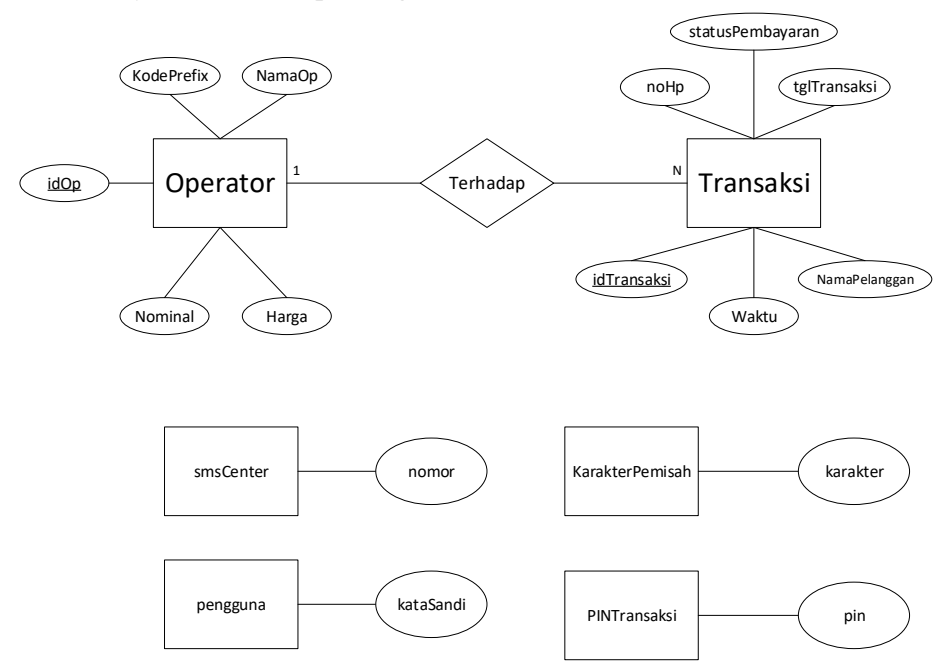

Gambar 3. Entity Relationship Diagram

Gambar 3 menunjukkan entitas-entitas beserta atribut serta relasi antar entitas yang ada pada aplikasi penjualan pulsa elektronik berbasis Android.

\section{F. Physical Data Modeling}
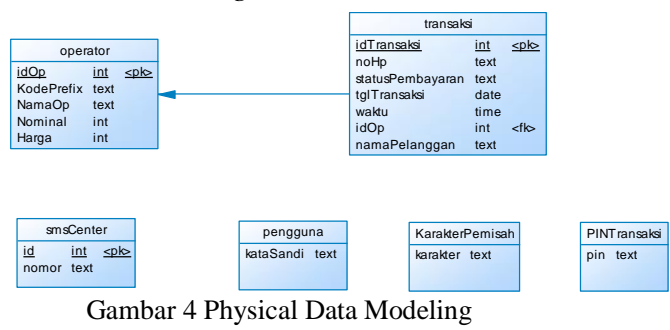

Gambar 4 menunjukkan tabel beserta atribut yang ada pada aplikasi penjualan pulsa elektronik berbasis Android. Terdapat 3 tabel yang disimpan kedalam basis data dan 3 tabel yang disimpan dalam bentuk file. Tabel yang disimpan kedalam basis data adalah tabel operator yang digunakan untuk menyimpan data kode prefix, nama operator, nominal, dan harga pulsa, tabel transaksi yang digunakan untuk menyimpan data transaksi dimana id pulsa pada tabel transaksi digunakan untuk mengambil data pulsa yang ada pada tabel pulsa, dan tabel SMS Center yang digunakan untuk menyimpan nomor SMS Center sebagai nomor tujuan permintaan pengiriman pulsa pelanggan pada saat proses transaksi pengiriman pulsa dan juga untuk permintaan pengecekan sisa saldo penjual. Sedangkan tabel yang 
disimpan dalam bentuk file adalah tabel pengguna yang digunakan untuk menyimpan kata sandi aplikasi, tabel karakterPemisah yang digunakan untuk menyimpan karakter pemisah pada format kode transaksi pengisian pulsa, dan tabel PINTransaksi yang digunakan untuk menyimpan pin transaksi pengisian pulsa.

\section{HASIL DAN PENGUJIAN}

Berdasarkan hasil pengujian maka dapat dievaluasi beberapa hal:

1. Dari 16 Fungsional yang ada semuanya telah berhasil diemplementasikan dan berfungsi dengan baik

2. Dalam proses transaksi, aplikasi mengirimkan SMS permintaan pengisian pulsa pelanggan ke server penyedia pulsa dan pulsa pelanggan berhasil terisi. Kemudian datadata transaksi yang dilakukan tersimpan dan selanjutnya digunakan untuk perhitungan pendapatan penjual pulsa dan sebagai arsip transaksi pengisian pulsa.

\section{KESIMPULAN DAN SARAN}

\section{A. Kesimpulan}

Berdasarkan tahapan analisis, implementasi, dan hasil pengujian yang telah didapat sebelumnya, maka diperoleh kesimpulan sebagai berikut:

1. Fungsi login pada aplikasi bekerja dengan baik untuk mengamankan data yang ada pada aplikasi sehingga aplikasi tidak dapat diakses oleh sembarang orang, khususnya untuk data laporan hutang.

2. Fitur transaksi pengiriman pulsa telah diuji dan berhasil mengirimkan permintaan pengiriman pulsa kepada server penyedia pulsa sesuai dengan format yang berlaku dan pulsa pelanggan berhasil diisi.

3. Menyediakan laporan riwayat transaksi dan total pendapatan penjual pulsa pada bulan tertentu sehingga bisa digunakan untuk menggantikan sistem transaksi secara manual dengan menulis dibuku catatan penjualan.

4. Fitur hutang telah berhasil digunakan untuk mengelola data pelanggan yang belum melunasi pembayaran.

\section{B. Saran}

Penulis menyadari masih banyak kekurangan yang ada pada aplikasi penjualan pulsa elektronik ini. Oleh karena itu, untuk meningkatkan kinerja dan kemampuan aplikasi yang dibangun agar menjadi aplikasi yang benar-benar handal, penulis memiliki beberapa saran sebagai berikut :

1. Diharapkan peneliti selanjutnya dapat menambahkan fitur penambahan saldo/stok

2. Transaksi bisa dilakukan dengan menggunakan SIM 1 maupun SIM 2

3. Menambahkan fitur pencarian SMS masuk dan pencarian nama pelanggan hutang

4. Tampilan aplikasi agar dibuat lebih menarik

\section{DAFTAR PUSTAKA}

[1] A.S, Rosa \& Shalahuddin, M. (2011). Modul Pembelajaran Rekayasa Perangkat Lunak (Terstruktur dan Berorientasi Objek). Bandung: Modula.

[2] Fowler, M. (2005). UML Distilled: Panduan Singkat Bahasa Pemodelan Objek Standar (3 ed.). Yogyakarta: Andi.

[3] Henderi. (2007). Diktat Kuliah UML STMIK AMIKOM. Bandung: STMIK AMIKOM.

[4] Purba, A. E., Budi, A. S., \& Prasetyo, D. T. (2015). Aplikasi Penjualan Pulsa Elektronik. Batam: Politeknik Negeri Batam.

[5] Safaat H., N. (2011). Pmrograman Aplikasi Mobile Smartphone dan Tablet PC Berbasis Android. Bandung: Informatika.

[6] Setya, I. B. (2015). Aplikasi Penjualan Pulsa Elektronik Berbasis Android. Sidoarjo: Universitas Muhammadiyah Sidoarjo

[7] Supardi, Y. (2014). Semua Bisa Menjadi Programmer Android. Jakarta: PT Elex Media Komputindo.

[8] Wahana Komputer. (2013). Shotcourse Series : Android Programming with Eclipse. Semarang: Penerbit Andi.

[9] Wibisono, G., Kurniawan Usman, U., \& Hantoro, G. D. (2008). Konsep Teknologi Seluler. Bandung: Informatika.

[10] Yulianti, E., \& Rusyiatno, T. (2013, April). Rekayasa Perangkat Lunak Penjualan Pulsa Electric Berbasis SMS Menggunakan Visual Basic. TEKNOIF, 1 